\title{
Adsorption of atrazine from aqueous solution using unmodified and modified bentonite clays
}

\author{
Oluwaseun Jacob Ajala ${ }^{1} \cdot$ Friday Onyekwere Nwosu ${ }^{1} \cdot$ Rasheed Kayode Ahmed $^{1}$
}

Received: 12 April 2018 / Accepted: 16 October 2018 / Published online: 30 October 2018

(C) The Author(s) 2018

\begin{abstract}
Properties of raw bentonite clay of Afuze in Edo state which are abundant and cheap bentonite mineral in Nigeria as adsorbents for the removal of atrazine in aqueous solution were investigated. The bentonite clay-types were characterized using scanning electron microscopy (SEM), Fourier transform infrared (FTIR) spectrophotometry and X-ray diffraction (XRD). Batch adsorption experiments were carried out to determine the equilibrium characteristics, thermodynamics and kinetics of the sorption processes. The data obtained were subjected to Langmuir, Freundlich and Temkin isotherm equations, while pseudo-first-order, pseudo-second-order rate equations, intra-particle diffusion and Elovich models were considered for kinetics and mechanism. The results showed that the adsorption processes were described by different isotherm models; they were all spontaneous ( $\Delta G$ ranges from -938.34 to $-6263.58 \mathrm{~kJ} / \mathrm{mol}$ ) and exothermic (range of $\Delta H$ is -252.73 to $-1057.08 \mathrm{~kJ} / \mathrm{mol}$ ), and with decreased randomness, $\Delta S(-3.110$ to $-0.581 \mathrm{~J} \cdot \mathrm{mol} / \mathrm{K})$. Pseudo-second-order kinetics model gave the better fit for all the sorption processes which implies physisorption process as the rate limiting step. Thus, bentonite clay-types can be used to adsorb atrazine.
\end{abstract}

Keywords Atrazine $\cdot$ Bentonite clay $\cdot$ Kinetics $\cdot$ Isotherm $\cdot$ Thermodynamics

\section{Introduction}

Frequent usage of herbicides (i.e. atrazine) at the home, farm land, school field, etc., and discharge of its wastewater from the producing industries into surface water bodies have become endangered to our ecosystem (i.e. aquatic organism and human). The major sources of atrazine in surface and underground water system are industrial effluents, domestic wastewaters, agricultural effluents and spillage of chemicals from anthropogenic activities (Kolpin et al. 1997; Miller et al. 2000). Continuous exposure to atrazine in water may cause cancer, endocrine disrupter and mammary gland tumour. Humans and living organisms can also suffer mutagenesis and carcinogenesis as a result of atrazine contamination (EPA 1990). Although it has been banned in most European countries, it is still one of the most widely used herbicides in the USA and also registered in more than

Oluwaseun Jacob Ajala

oluwaseun_ajala81@yahoo.com

1 Analytical Environmental Chemistry Unit, Department of Industrial Chemistry, Faculty of Physical Sciences, University of Ilorin, P.M. B. 1515, Ilorin, Nigeria
70 countries worldwide (Kauffmann et al. 2000). It has been in use since 1958 as a pre- and post-emergent herbicide to control broad-leaved weeds in production of corn and sorghum (Jone et al. 1982). Atrazine is a probable human carcinogen, and its current maximum contaminant level in drinking water established by the environmental protection agency is $3.0 \mu \mathrm{g} / \mathrm{L}$.

The atrazine pollutants in most wastewater could be treated using advanced oxidation process (AOPs) (Xu et al. 2013); adsorption principles have been found useful for removal of atrazine polluted wastewater (Liu et al. 2015). Among others, selective adsorptions that make use of biological materials and active carbon have created great interest among the researchers.

Active carbon can be used to adsorb organic pollutants because of its large surface but exhibits higher disposal cost and usually difficult to prepare and exhibit higher disposal cost (Burleigh et al. 2002). The economical cost of active carbon made scientist to search for the development of adsorbents from cheaper raw materials. These include biochar prepared from tamarind nut (Nwosu et al. 2017) for the removal of triazine compounds. Therefore, the preparations of good adsorbents via clay such as bentonite for removal 
of different concentration of atrazine molecule become important.

The main aim of this study is to prepare a low cost, constant available and environmentally safe adsorbent from bentonite clay and use for removal of atrazine from wastewater. Thus, the bentonite clay which is always available without season effect was converted into adsorbents. Batch adsorption, adsorption data, kinetics studies and thermodynamic were carried out.

\section{Materials and method}

\section{Adsorbents}

The bentonite clay was utilized for the preparation of the adsorbents. The bentonite clay which was collected from major deposit of Afuze in Edo state, south -west region of Nigeria with longitude and latitude of $6^{\circ} 56^{\prime 2} 24.2^{\prime \prime} \mathrm{N}$ and $5^{\circ} 59^{\prime} 07.7^{\prime \prime}$, respectively.

\section{Preparation of adsorbents}

Raw bentonite clay was washed with distilled water to remove impurities until its $\mathrm{pH}$ reaches 7 , and it was further air-dried, oven-dried and then crushed into small sizes and sieved to $<250 \mu \mathrm{m}$ to make unmodified (pretreated) bentonite clay type (UBC). While a known quantity $(50.0 \mathrm{~g})$ of unmodified (pretreated) bentonite clay was impregnated with $2 \mathrm{M} \mathrm{H}_{2} \mathrm{SO}_{4}$ and $\mathrm{NaOH}$ differently using ratio 1:2 w/v. It was shaken vigorously using a Uniscope SM 101 shaker water bath for $24 \mathrm{~h}$ at $30{ }^{\circ} \mathrm{C}$ and then washed with distilled water to remove the excess acid until its effluent become neutral ( $\mathrm{pH}=7$ ). (Nwosu et al. 2018, Abu-Elella et al. 2015). It was then filtered under vacuum and dried in oven at $376 \mathrm{~K}$ for $8 \mathrm{~h}$. The dried samples were grounded and stored in airtight sample bottle (Nwosu et al. 2018, Gómez-Tamayo et al. 2008 ) to produce $2 \mathrm{M}$ sulphuric acid modified bentonite clay (2-ABC) and $2 \mathrm{M}$ sodium hydroxide modified bentonite clay (2-BBC), respectively.

\section{Characterization of unmodified and modified bentonite clay-types}

Chemical and mineralogical compositions were characterized by Fourier transform infrared (FTIR) a Perkin Elmer 1600 Series FTIR spectrophotometer model 1615, X-ray diffraction (XRD) model 6000 machine and scanning electron microscope (SEM) using a Phenom World scanning electron microscope for functional group (Austin and Hoang 2009), structure (Ramachandran and Beaudoin 2008) and physical morphology (Mullan 2006) of the modified and unmodified clay-types, respectively.

\section{Adsorbate}

The primary adsorbate in this study is atrazine and its structure is in fig 1. The International union of Pure and Applied Chemistry name of atrazine is 2-chloro-4-(ethylamino)-6(isopropylamino)-1, 3, 5-triazine. The following are the physicochemical of atrazine based on their relevant on environment; melting point: $175-177{ }^{\circ} \mathrm{C}$, density: $1.187 \mathrm{~g} /$ $\mathrm{cm}^{3}$ at $20{ }^{\circ} \mathrm{C}$, water solubility: $7 \mathrm{mg} / 100 \mathrm{ml}, \log$ octanolwater partition coefficient: 2.3 , vapour pressure: $40 \times 10^{-6}$ pa at $20{ }^{\circ} \mathrm{C}$, molar mass: $215.69 \mathrm{~g} / \mathrm{mol}$ boiling point: $200{ }^{\circ} \mathrm{C}$, appearance: colourless solid, molecular formula: $\mathrm{C}_{8} \mathrm{H}_{14} \mathrm{ClN}_{5}$. It is usually produced by synthesis but does not occur naturally (Tomlin 2000)

\section{Preparation of adsorbate}

Working aqueous solutions of different concentrations of atrazine were prepared by serial dilution using micropipettes and standard volumetric flasks from the stock solution of the atrazine $(1000 \mathrm{mg} / \mathrm{L})$ which was prepared by taken $1 \mathrm{~g}$ of atrazine and dissolved in $1 \mathrm{~L}$ of distilled water.

\section{Adsorption procedure}

In each of the factors studied, the atrazine uptake at equilibrium $q_{t}$ was calculated using the following expression:

$q_{t}=\frac{\left(C_{o}-C_{f}\right) v}{m}$

where $q_{t}$ is the quantity of atrazine uptake in $\mathrm{mg} / \mathrm{g}$, $\mathrm{v}$ is volume (L), $C_{o}$ and $C_{f}$ are the initial and final concentrations in $\mathrm{mg} / \mathrm{L}$, respectively. The sample bottles containing the mixture of various atrazine concentrations and the clay-types were separately removed from the water bath shaker and the solutions centrifuged to remove the adsorbent. The initial

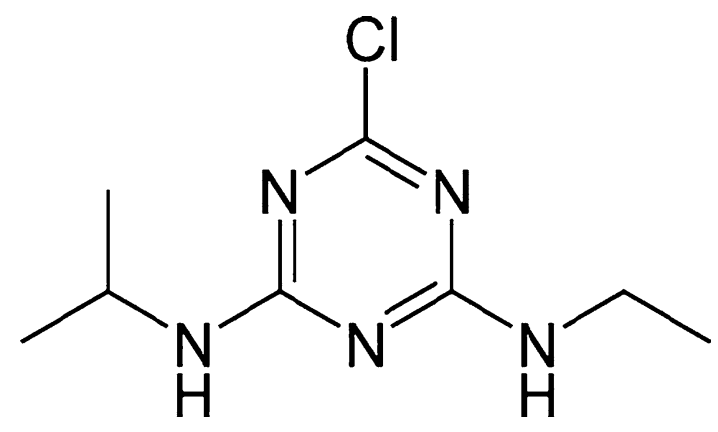

Fig. 1 Structure of atrazine molecule 
concentration and residual aqueous concentrations of atrazine were determined using UV-visible spectrophotometer (DU 640, BECKMAN) at $\kappa \max =273$. Prior to determination using UV-visible techniques, the effect of variables on adsorption capacities of UBC, 2-ABC and 2-BBC was carried out.

\section{Results and discussion}

\section{Adsorbent characterization}

Figure 2 represents the FTIR spectra of the three adsorbents, respectively. The sharp bands at $3696.17 \mathrm{~cm}^{-1}$ and $3626.39 \mathrm{~cm}^{-1}$ are attributed to the $\mathrm{N}-\mathrm{H}$ stretching for the $\mathrm{UBC}$ and 2-ABC types as it is the same as the peaks at 3697 and $3620 \mathrm{~cm}^{-1}$ reported by Georges-IVO, (2005). The peaks at $3436.41 \mathrm{~cm}^{-1}$ in the $2-\mathrm{ABC}$ sample and $3430.21 \mathrm{~cm}^{-1}$ in the UBC are assigned to $\mathrm{OH}$ stretching which is close to $3426 \mathrm{~cm}^{-1}$ and $3420 \mathrm{~cm}^{-1}$ reported by Isci et al. (2006) and Aroke et al. (2013).

The bands $1644.47 \mathrm{~cm}^{-1}$ and $1637.99 \mathrm{~cm}^{-1}$ that present UBC and 2-ABC samples are assigned to the $\mathrm{H}-\mathrm{O}-\mathrm{H}$ bending of water which fit within range reported at peaks $1620 \mathrm{~cm}^{-1}-1642 \mathrm{~cm}^{-1}$ by Bhasker and Gopalakrishnarao (2010). The peaks observed at $1042.89 \mathrm{~cm}^{-1}, 1036.41 \mathrm{~cm}^{-1}$ and $1029.58 \mathrm{~cm}^{-1}$ are assigned to the characteristic bands of silicate which are greatly related to the stretching vibrations of Si-O. The peaks at $913.08 \mathrm{~cm}^{-1,} 916.09 \mathrm{~cm}^{-1}$ and $912.55 \mathrm{~cm}^{-1}$ are responsible for $\mathrm{Al}-\mathrm{Al}-\mathrm{OH}$ group deformation and are similar to those of $913 \mathrm{~cm}^{-1}$ and $914 \mathrm{~cm}^{-1}$ reported by Amin et al. (2010). Figure 3 shows the SEM micrographs at $\times 500$ and $\times 1000$ magnifications for UBC, $2-\mathrm{ABC}$ and 2-BBC, respectively. It clearly indicated the presence of numerous pores on the surfaces of the modified clay-types adsorbents but is few on the surface of unmodified ones. The structures of the modified adsorbents are rough and irregular shapes which signify a favourable adsorption (Patel and Sudhakar 2008) compared to unmodified adsorbents which has a fine, smooth and regular shape. The XRD powder analysis for these various clay-types is presented in Fig. 4. There is a conspicuous peak at $2 \theta$ equal $18^{\circ}$, and $2 \theta$ equal $24^{\circ}$ for the $2-\mathrm{ABC}$ and $2-\mathrm{BBC}$, respectively, and showed that they are crystalline in nature.

\section{Influence of various factors on amount of atrazine uptake}

Effect of concentration Fig. 5a shows the effect of the initial concentration $\left(\mathrm{C}_{o} \mathrm{mg} / \mathrm{L}\right)$ of atrazine on the adsorption capacities of the prepared UBC, 2-ABC and 2-BBC, respectively. As indicated in Fig. 5(a), the amount adsorbed of these various clay-types increased from 23.15 to $138.75 \mathrm{mg} / \mathrm{g}, 23.7$
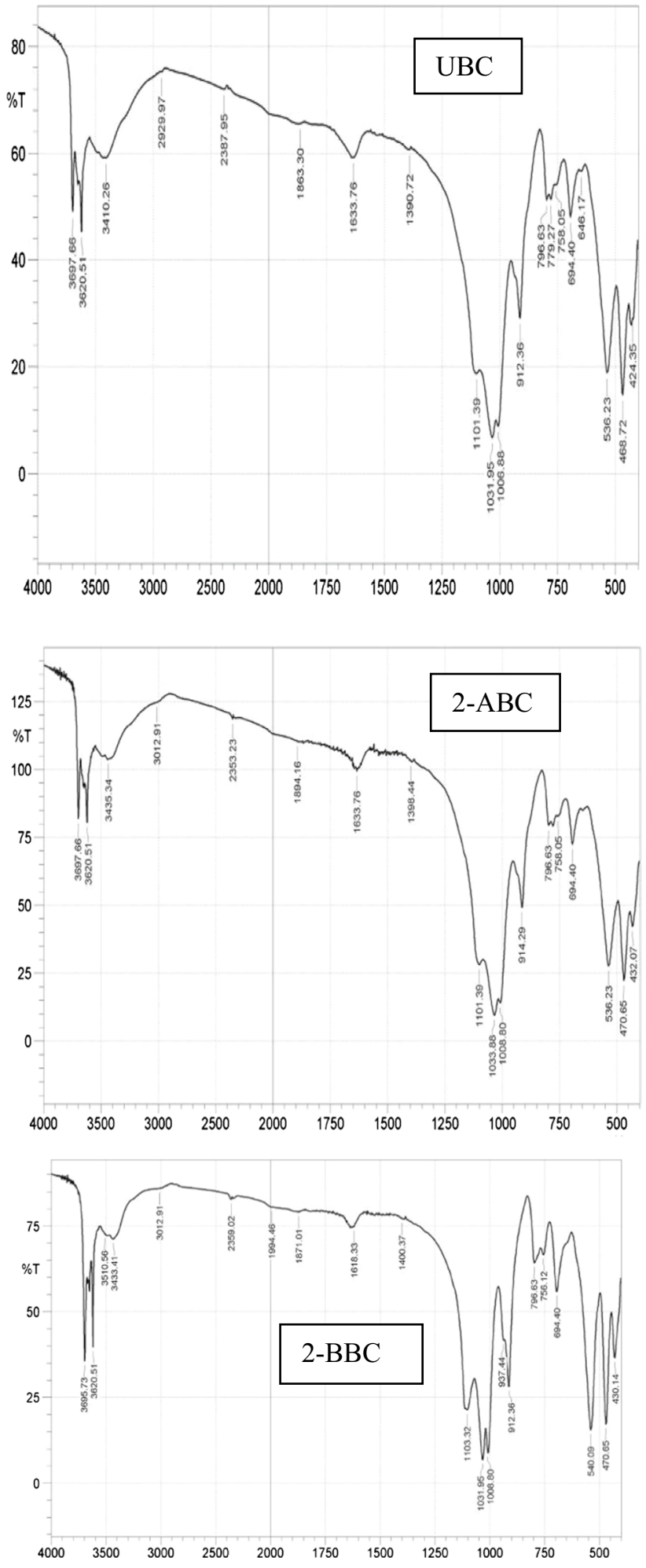

Fig. 2 FTIR spectra of various bentonite clay-types

to $227.65 \mathrm{mg} / \mathrm{g}$ and 22.3 to $267.85 \mathrm{mg} / \mathrm{g}$ as atrazine concentration increased from 100 to $1000 \mathrm{mg} / \mathrm{L}$, from 100 to $1500 \mathrm{mg} / \mathrm{L}$ and 100 to $1500 \mathrm{mg} / \mathrm{L}$ for UBC, 2-ABC and 

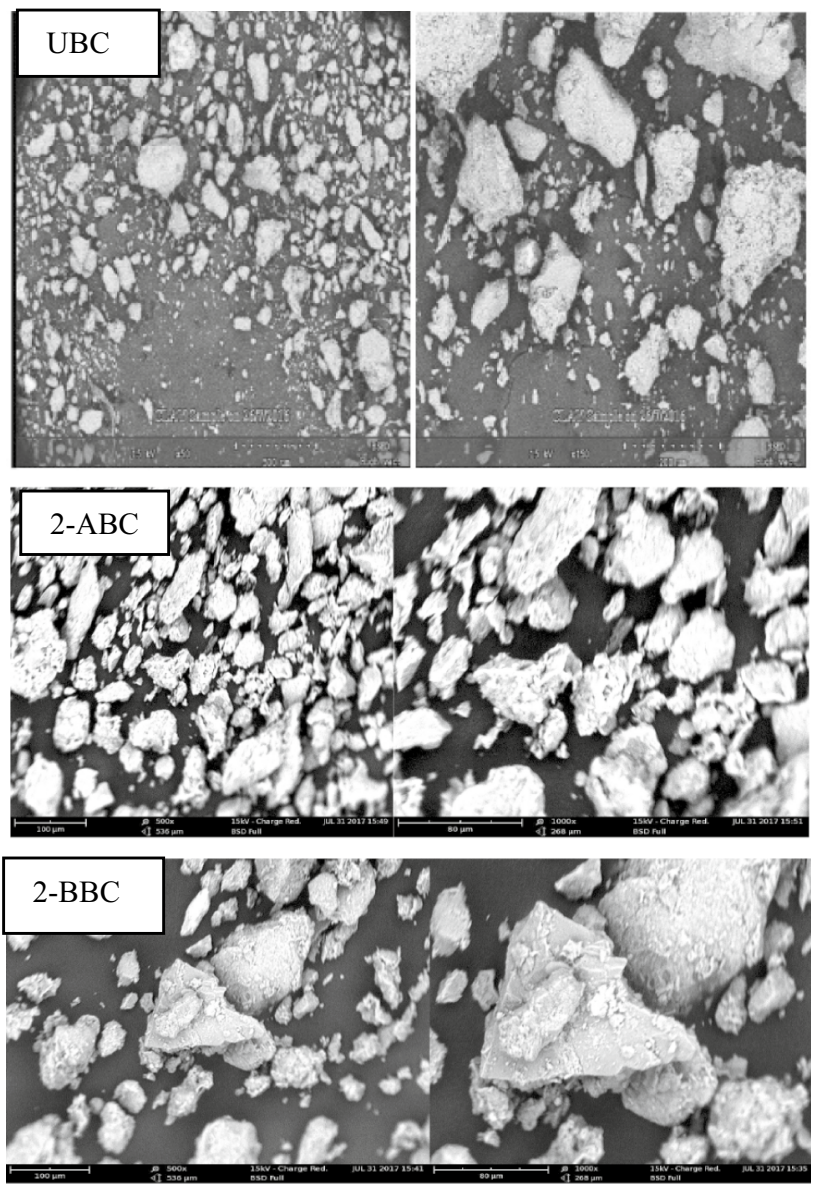

Fig. 3 SEM Micrograph of UBC, 2-ABC and 2-BBC, respectively, at $\times 500$ and $\times 1000$ magnifications

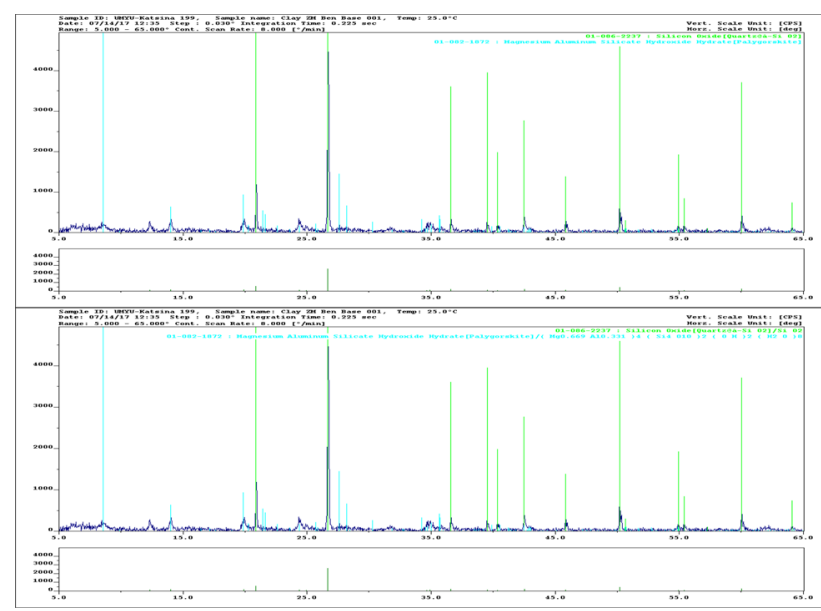

Fig. 4 XRD Spectra of 2-ABC and 2-BBC, respectively

2-BBC, respectively. This may be due to the increases in the initial concentration of atrazine which can provide an important driving force to overcome all mass transfer resistances of atrazine between adsorbate solution and the adsorbent surface (Hatem et al. 2012). Therefore, the rate of atrazine molecules that travels from the bulk solution to the particle surface increases.

Similar trends have been reportedly observed in the adsorption of $P$-nitrophenol using active carbon produced from different precursors that are known (Nwosu et al. 2017). Further increase in adsorbate brought a slight decrease in the amount of adsorbed, and thus, concentrations of $800 \mathrm{mg} / \mathrm{L}, 1100 \mathrm{mg} / \mathrm{L}$ and $1100 \mathrm{mg} / \mathrm{L}$ were chosen as equilibrium concentration for UBC, 2-ABC and 2-BBC, respectively.

Effect of contact time The effect of contact time of adsorbents is important in adsorption processes because it exercises a great deal of influence on the adsorption capacity of adsorbents. Figure $5 \mathrm{~b}$ shows the variation in the quantity of atrazine adsorbed by $0.1 \mathrm{~g}$ of UBC, $2-\mathrm{ABC}$ and 2-BBC at $303 \mathrm{~K}$ with time. The rate at which adsorption occurred was rapid initially between 5 and $30 \mathrm{~min}$, and became slower between 60 and $200 \mathrm{~min}$. This phenomenon may be due to a large number of available vacant surface sites for adsorption during the initial stage, and after a lapse of time, remaining vacant surface sites were difficult to be occupied due to repulsive force between solute molecules on the solid and bulk phases (Ahmed et al. 2007). The high adsorption rate at the beginning of adsorption process by $0.1 \mathrm{~g} \mathrm{UBC}, 2-\mathrm{ABC}$ and 2-BBC separately may also be due to the adsorption of atrazine by exterior surface of the adsorbent. When saturation was reached at the exterior surface, the atrazine molecules would then enter the pores of adsorbent and become adsorbed by the interior surface of the particles. This phenomenon takes relatively longer contact time $(3 \mathrm{~h})$ to reach equilibrium (Sathishkumar et al. 2007).

Effect of adsorbent dose Figure 5d shows the adsorbent dose profile diagram for both adsorbents (UBC, 2-ABC and 2-BBC). The amount of atrazine adsorbed per gram of these different clay-types decreased with increasing adsorbent dose. It decreased from 230.2 to $29.73 \mathrm{mg} / \mathrm{g}$, from 283 to $74.37 \mathrm{mg} / \mathrm{g}$ and from 263.5 to $50.74 \mathrm{mg} / \mathrm{g}$ for UBC, $2-\mathrm{ABC}$ and 2-BBC, respectively, when adsorbent dose increased from 0.05 to $0.35 \mathrm{~g}$. Thus, for the remainder of the research, adsorbent dose of $0.1 \mathrm{~g}$ was used as the optimized adsorbent dose. This is similar to adsorbent dose reported in the adsorption process of PNP using active carbon from coconut husk (Nwosu et al. 2017).

Effect of $\mathrm{pH}$ of the solution Adsorption was reported to be affected by the $\mathrm{pH}$ of the adsorbents on atrazine as shown in Fig. 5(c); the adsorption of atrazine on UBC and 2-ABC increases from $\mathrm{pH} 2$ to 12 , while for 2-BBC it increases from $\mathrm{pH} 2$ to 7 and reduced from $\mathrm{pH} 7$ to 12 . The values of pHpzc for the UBC, 2-ABC and 2-BBC are 6.2, 7.0 and 7.8, respectively. It has been reported that sorption of cations is favoured at $\mathrm{pH}>\mathrm{pHpzc}$, while the sorption of anion is favoured at $\mathrm{pH}<\mathrm{pHpzc}$. The specific adsorption of cations 

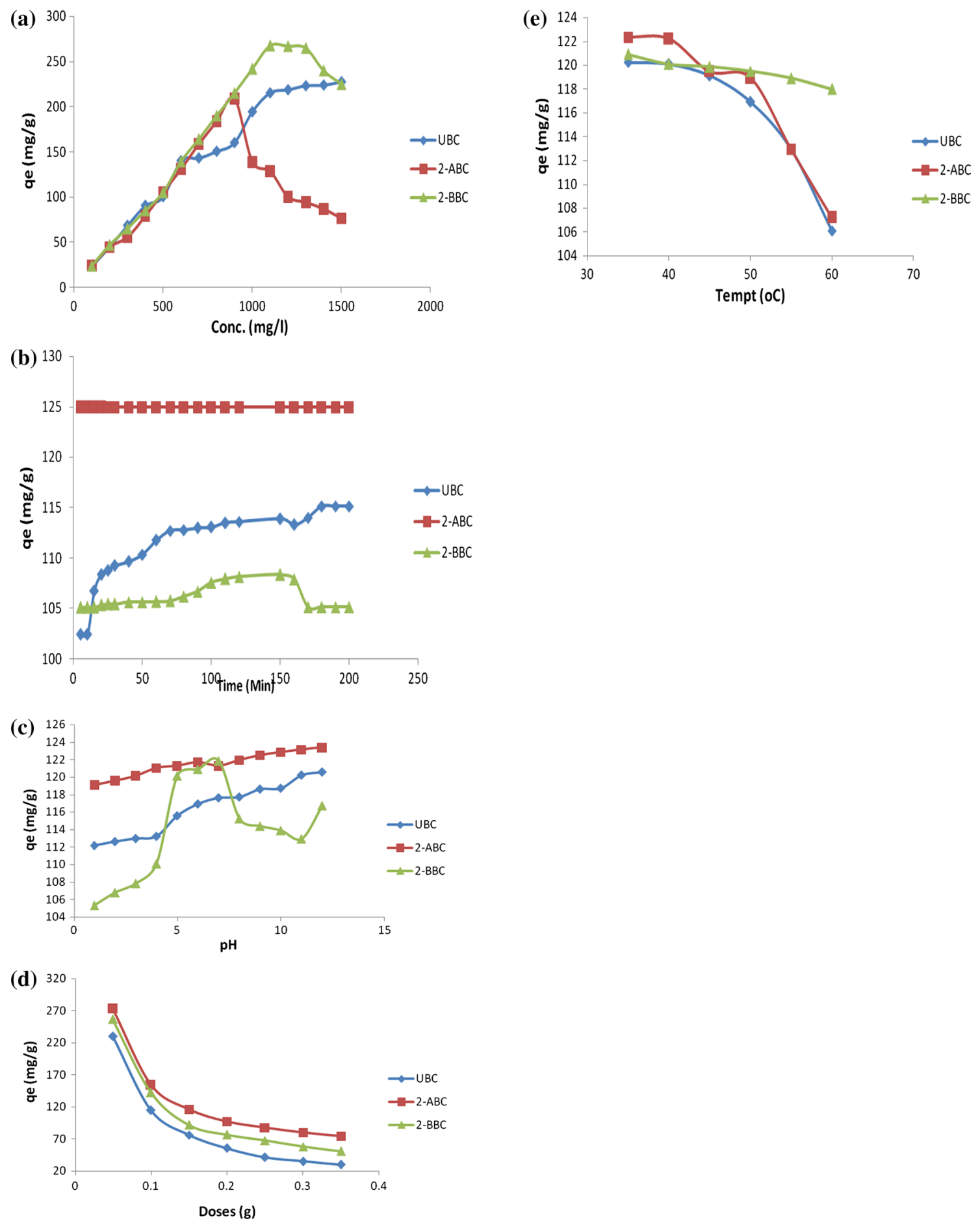

Fig. 5 Effect of adsorption conditions on adsorption capacities of the active carbons. a Initial concentration; $\mathbf{b}$ contact time; $\mathbf{c} \mathrm{pH}$; $\mathbf{d}$ adsorbent dosage; e temperature

shifts pHpzc towards lower values, whereas the specific adsorption of anion shifts pHpzc towards higher value (Mall et al. 2006). The low uptake capacities at low $\mathrm{pH}$ values can be attributed to the fact that at low $\mathrm{pH}$, the adsorbent surface is completely covered by $\mathrm{H}^{+}$increasing the competition for the available adsorption sites with atrazine molecule which cannot compete with them for adsorption site. This could be partly due to the fact that protons are strong competing adsorbate because of their higher concentration. However, at the high $\mathrm{pH}$ value, the surface of the adsorbent is saturated 
with negative charge which enhances the adsorption of positively charged atrazine onto the surface of the adsorbents (Liu et al. 2015).

Effect of temperature Plots of the amount adsorbed at equilibrium, $q_{e}(\mathrm{mg} / \mathrm{g})$ versus absolute temperature (T K) are shown in Fig. 5e for UBC, 2-ABC and 2-BBC. It can be seen from this figure that the amount adsorbed decreases with increasing temperature for the three adsorbents, indicating the apparent exothermic nature of the adsorption process. In the liquid phase, an increase in temperature commonly increases the solubility of the molecules and their diffusion within the pores of the adsorbent materials is hampered, and hence, at higher temperature adsorbed molecules tend to desorb suggesting physisorption (Nwosu et al. 2017, Tang et al. 2007). The adsorption capacity of UBC decreased from 120.25 to $106.1 \mathrm{mg} / \mathrm{g}$, for 2-ABC adsorption capacity decreased from 122.35 to $107.2 \mathrm{mg} / \mathrm{g}$, and for 2-BBC adsorption capacity decreased from 120.9 to $118 \mathrm{mg} / \mathrm{g}$; the temperature increases from 308 to $333 \mathrm{k}$.

\section{Equilibrium adsorption isotherms modelling}

The equilibrium experimental data obtained were fitted into three adsorption isotherm models, namely Langmuir, Freundlich and Temkin, and they all gave varying degree of success.

\section{The Langmuir adsorption isotherm model}

This is explained supposition of a homogeneous adsorbent surface with identical adsorption sites (Varank et al. 2012). The linearized form of Langmuir equation is given as:

$\left(\frac{1}{q_{e}}\right)=\left(\frac{1}{c_{e}}\right)\left(\frac{1}{b q \max }\right)+\left(\frac{1}{q \max }\right)$

The Langmuir plots of $1 / q_{e}$ versus $1 / C_{e}$ for both adsorbents are depicted in Fig. 6a and the Langmuir parameters obtained from the slope and intercept of the plots are listed in Table 2. The three adsorbents exhibited high correlation coefficient $R^{2}$ values of $0.907,0.969$ and 0.988 for UBC, 2-ABC and 2-BBC, respectively.

It can be observed from Table 1 that the $2-\mathrm{ABC}$ has an adsorption capacity $(125.00 \mathrm{mg} / \mathrm{g})$ higher than that of the 2-BBC $(111.11 \mathrm{mg} / \mathrm{g})$ and UBC $(76.92 \mathrm{mg} / \mathrm{g})$. Furthermore, a dimensionless separation factor $R_{L}$ equation is given in Eq. 3:

$R_{L}=\frac{1}{1+K_{L} C_{e}}$

It expresses the essential characteristic of the Langmuir equation and indicates the nature of adsorption process, and its value was found to be in between 0 and 1 as listed
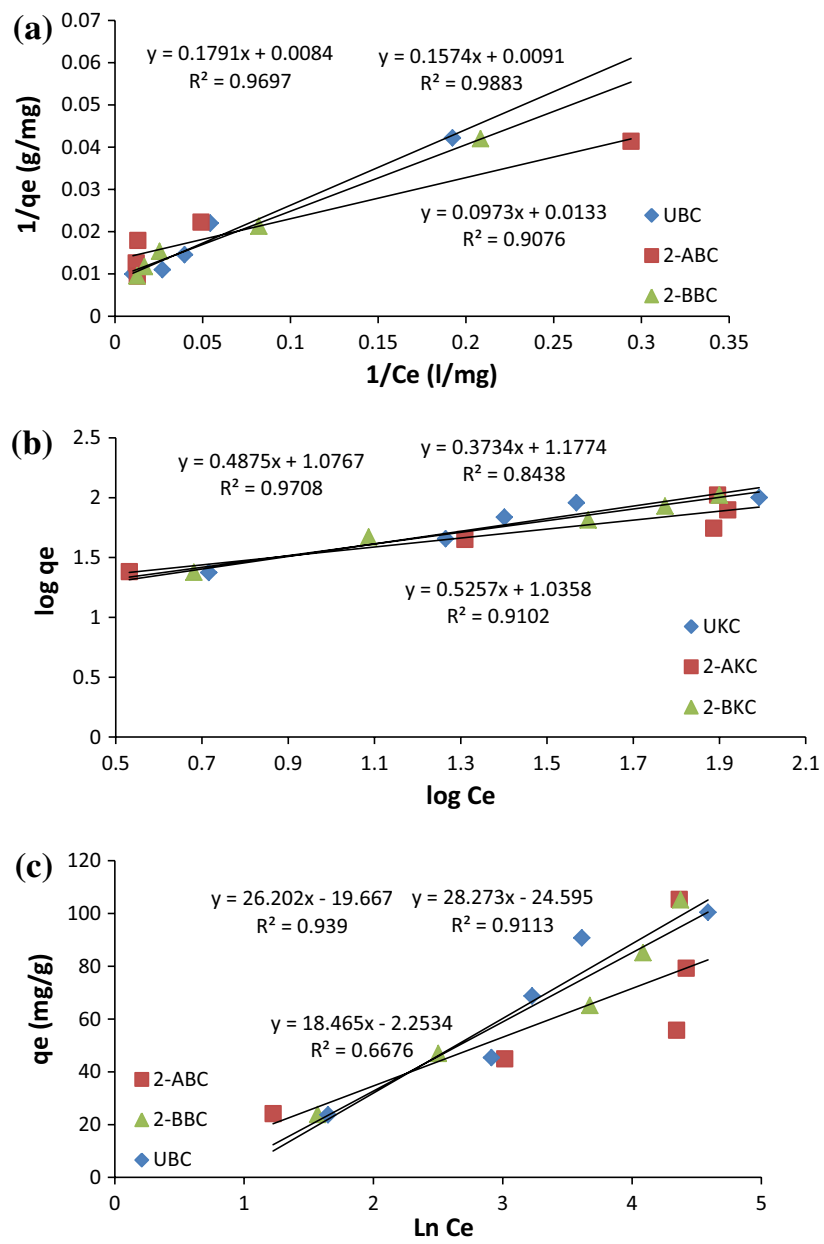

Fig. 6 Various adsorption isotherms for the removal of atrazine using UBC, 2-ABC and 2-BBC Types. (a) Langmuir; (b) Freundlich; (c) Temkin

Table 1 Adsorption Isotherm Parameters

\begin{tabular}{llll}
\hline Isotherm & $\mathrm{UBC}$ & $2-\mathrm{ABC}$ & $2-\mathrm{BBC}$ \\
\hline Langmuir & & & \\
$q_{\max }(\mathrm{mg} / \mathrm{g})$ & 76.92 & 125.00 & 111.11 \\
$K_{L}$ & 0.1340 & 0.0447 & 0.0573 \\
$R_{L}$ & 0.0694 & 0.1828 & 0.1486 \\
$R^{2}$ & 0.907 & 0.969 & 0.988 \\
Freundlich & & & \\
$K_{F}(\mathrm{mg} / \mathrm{g})$ & 15.031 & 10.839 & 11.912 \\
$1 / n$ & 0.373 & 0.525 & 0.487 \\
$R^{2}$ & 0.843 & 0.910 & 0.970 \\
Temkin & & & \\
$B$ & 18.46 & 28.27 & 26.20 \\
$b_{T}$ & 136.46 & 89.11 & 96.11 \\
$A_{T}(\mathrm{~L} / \mathrm{mg})$ & 0.8851 & 0.4190 & 0.4722 \\
$R^{2}$ & 0.667 & 0.911 & 0.939 \\
\hline
\end{tabular}


Table 2 Kinetic Parameters of Adsorption of Atrazine

\begin{tabular}{llll}
\hline Kinetic model & UBC & 2-ABC & 2-BBC \\
\hline Pseudo-first & & & \\
$k_{1}\left(\mathrm{~min}^{-1}\right)$ & 0.0253 & 0.0253 & 0.000 \\
$q_{e}(\mathrm{mg} / \mathrm{g})$ & 14.06 & 0.05 & 8.26 \\
$R^{2}$ & 0.848 & 0.895 & 0.917 \\
Pseudo-second & & & \\
$k_{2}\left(\mathrm{gmg}^{-1} \mathrm{~min}^{-1}\right)$ & 0.0162 & 3.200 & 0.000 \\
$q_{e}(\mathrm{mg} / \mathrm{g})$ & 111.11 & 125.00 & 111.11 \\
$R^{2}$ & 0.999 & 1.00 & 1.00 \\
Intra-particle diffusion $^{2}$ & & & \\
$k_{i}(\mathrm{mg} / \mathrm{gmin}$ & \\
$C$ & 1.471 & 0.003 & 0.146 \\
$R^{2}$ & 100.6 & 124.9 & 104.6 \\
Elovich & 0.896 & 0.799 & 0.873 \\
A & & & \\
$B$ & $3.95 \times 10^{12}$ & $1.93 \times 10^{52}$ & $6.58 \times 10^{44}$ \\
$R^{2}$ & 0.287 & 90.91 & 3.676 \\
\hline
\end{tabular}

in Table 1. This confirms that the adsorption of atrazine is favourable on the three adsorbents. These are the reasons: on the surface of the adsorbent, monolayer was formed with minimal interaction among molecules of adsorbate, immobile and localized adsorption and all the sites having equal adsorption energies ( $\mathrm{Li}$ et al. 2011).

\section{Freundlich adsorption isotherm model}

This model suggests neither homogeneous site energies nor limited levels of adsorption which implies that it can describe the experimental data of adsorption isotherm whether adsorption occurs on homogeneous or heterogeneous sites and it is not controlled by the formation of the monolayer (Halif et al. 2007). The linearized Freundlich equation is given as:

$\log \frac{x}{m}=\log K+\frac{1}{n} \log C_{e}$

From the slope and intercept of the linear plots of $\ln \mathrm{q}_{e}$ versus $\ln C_{e}$, Fig. 5b, Freundlich parameters $K_{F}$ and $1 / n$ indicating the measures of adsorption capacity of UBC, 2-ABC and 2-BBC and its intensity of adsorption, respectively, were obtained and listed with the correlation coefficient value, $R^{2}$ (Table 1).

The results revealed that the adsorption of atrazine on UBC, 2-ABC and 2-BBC obeys both Freundlich and Langmuir adsorption isotherms, as indicated by high $\mathrm{R}^{2} \mathrm{Val}-$ ues $(>0.9)$ except of Freundlich isotherm of UBC with a fair $R^{2}$ value (0.84). Moreover, the Freundlich constant
( $K_{F}=15.031 \mathrm{mg} / \mathrm{g}$ ) of UBC is larger than that obtained of 2-BBC $\left(K_{F}=11.912 \mathrm{mg} / \mathrm{g}\right)$, while $2-\mathrm{BBC}$ is also larger than of $2-\mathrm{ABC}\left(K_{f}=10.839 \mathrm{mg} / \mathrm{g}\right)$. The results indicated that 2-BBC has higher adsorption affinity towards atrazine than $\mathrm{UBC}$ and $2-\mathrm{ABC}$. The value of $1 / \mathrm{n}$ indicates a favourable adsorption when $0<1 / n<1$ (Halif et al. 2007). The adsorption intensity $1 / \mathrm{n}$ is found to be $0.373,0.525$ and 0.487 for $\mathrm{UBC}, 2-\mathrm{ABC}$ and 2-BBC, respectively. It is observed that all the three adsorbents satisfy the conditions of heterogeneity.

\section{Temkin adsorption isotherm}

It suggests that the heat of adsorption of all the molecules in the layer is inversely proportional to coverage of the adsorbent surface which might be attributed to adsorbate species-adsorbent interactions. A uniform distribution of binding energies up to some maximum binding energy is the characteristics of Temkin adsorption (Tempkin and Pyzhev 1940). The linear form of the Temkin isotherm is represented in Eq. (5):

$q_{e}=\frac{R T}{b_{T}} \ln A_{T}+\left(\frac{R T}{b_{T}}\right) \ln C_{e}$

and

$B=\frac{R T}{b_{T}}$

Figure $6 \mathrm{c}$ depicts the Temkin isotherm plots for the atrazine uptake onto the $\mathrm{UBC}, 2-\mathrm{ABC}$ and 2-BBC from which the relevant Temkin adsorption isotherm values are obtained and are shown with values of correlation coefficients in Table 1 . The $B_{T}$ values indicate the heat of adsorption obtained as $136.46,89.11$ and 96.15 for UBC, 2-ABC and $2-\mathrm{BBC}$, respectively, while $A_{T}$ representing the equilibrium binding energy are $0.8851(\mathrm{~L} / \mathrm{mg}), 0.4190(\mathrm{~L} / \mathrm{mg})$ and $0.4722(\mathrm{~L} / \mathrm{mg})$ for UBC, 2-ABC and 2-BBC, respectively. Thus, these values imply that the atrazine is more strongly adsorbed on the UBC surface than that of 2-ABC and $2-\mathrm{BBC}$, indicating that there is a stronger interaction between atrazine and the respective bentonite clays. Similar results have been reported as per the adsorption of $N$-nitrophenol using Pili nut shell-derived active carbon (Nwosu et al. 2017). They reported $B_{T}$ value of 24.292 and $A_{T}$ value of 0.162 .

\section{Adsorption kinetics studies}

The kinetic experimental data obtained for the adsorption of atrazine on UBC, 2-ABC and 2-BBC were interpreted by means of pseudo-first-order, pseudo-second-order, 
intra-particle diffusion and Elovich kinetic models in figure 7.

\section{Pseudo-first-order and pseudo-second-order kinetic models}

The linear forms of pseudo-first-order and pseudo-secondorder kinetic model equations are given in Eqs. 7 and 8.

$\log \left(q_{e}-q_{t}\right)=\log q_{e}-\frac{k_{1} t}{2.303}$

$\frac{t}{q}=\frac{1}{k_{2} q_{e}^{2}}+\frac{1}{q_{e}}$

The plot of linearized form of the equation is shown in Fig. 6a. The pseudo-first-order rate constant $k_{l}$, amount of atrazine adsorbed at equilibrium $q_{e}$ and correlation coefficients are shown in Table 2. The results showed that their correlation coefficients $R^{2}$ obtained for UBC, 2-ABC and 2-BBC for pseudo-first-order kinetics model are $0.848,0895$ and 0.917 , respectively, which are lower than their corresponding pseudo-second-order kinetics model $\left(R^{2}=0.999\right.$, 1.000 and 1.000). Therefore, adsorption of atrazine onto these various bentonite clay-types revealed that pseudosecond-order kinetic model is better to explain the kinetic adsorption process than pseudo-first-order kinetic model. This may be due to the fact the adsorption rate of atrazine onto the three clay adsorbents depends on the behaviour over a whole range of adsorption process. Figure 6 (b) shows the plots of $t / q$ against $t$, and the resulting kinetic parameters are presented in Table 2. The calculated values of $q_{e}$ were closer to the experimental $q_{e}$ values for UBC, 2-ABC and 2-BBC.

The transfer of solute molecules on to solid surface particulates from the aqueous phase, and then, diffusion of the solute molecules into the pore interiors could be described by the intra-particle diffusion rate equation and is given as (Bohli et al. 2013).

$q_{t}=k_{\mathrm{id}} t^{1 / 2}+C$

where $k_{\text {id }}$ and $C$ are the intra-particle diffusion rate constant and boundary layer thickness, respectively. The plotting $q_{t}$ against $t^{1 / 2}$ as shown in Fig. 6(c) indicates the effect of either film pore diffusion or intra-particle diffusion. The general features of an initial step linear portion and plateau are attributed to the bulk diffusion; intra-particle diffusion and the plateau portion represent the equilibrium. The magnitudes of $k_{\text {id }}, \mathrm{C}$ and the corresponding regression coefficients of the three adsorption system are listed in Table 3 . The pore diffusion rate constant $k_{\text {id }}$ values: $1.377 \mathrm{mg} / \mathrm{g} \mathrm{min}{ }^{1 / 2}$, $0.003 \mathrm{mg} / \mathrm{g} \mathrm{min}{ }^{1 / 2}$ and $0.146 \mathrm{mg} / \mathrm{g} \mathrm{min}^{1 / 2}$, indicated substantial diffusion of atrazine onto UBC , 2-ABC, and 2-BBC, respectively.

The existence of linear relationship between amount qe against $t^{1 / 2}$ indicates that intra-particle diffusion participated during the adsorption process. If the straight line of the plot of qe against $t^{1 / 2}$ passes through the origin, then intra-particle diffusion becomes the controlling step. The pore diffusion rate constants of $0.46 \mathrm{mg} / \mathrm{g} \mathrm{min}{ }^{1 / 2}$ and $0.161 \mathrm{mg} / \mathrm{g} \mathrm{min}^{1 / 2}$ in the adsorption of $P$-nitrophenol with zeolite and bentonite have been obtained (Varank et al. 2012). This is similar to the adsorption of Direct Red Dye 81 with bamboo sawdust and treated bamboo sawdust where $k_{\text {id }}$ values of $0.32 \mathrm{mg} / \mathrm{g} \mathrm{min} \mathrm{m}^{1 / 2}$ and $0.62 \mathrm{mg} / \mathrm{g} \mathrm{min}{ }^{1 / 2}$ were obtained.

Moreover, $k_{\text {id }}$ value of $3.2479 \mathrm{mg} / \mathrm{g} \mathrm{min}^{1 / 2}$ has been obtained in the adsorption of phenol using active carbon from olive stones (Bohli et al. 2013). The adsorption of $P$-nitrophenol using active carbon fibre and granular active carbon gave similar result obtained in this study with $k_{\text {id }}$ values of $8.924 \mathrm{mg} / \mathrm{g} \mathrm{min}^{1 / 2}$ and $11.91 \mathrm{mg} / \mathrm{g} \mathrm{min}^{1 / 2}$, respectively (Nwosu et al. 2017).

The adsorption data could also be treated using Elovich equation that is shown in Eq. 10 (Varank et al. 2012):

$\frac{d q_{t}}{d t}=\alpha \mathrm{e}^{\beta q_{t}}$

This on linearizing and simplifying can be written as:

$q_{t}=\frac{1}{\beta} \ln (\alpha \beta)+\frac{1}{\beta} \ln (t)$

where $\alpha(\mathrm{mg} / \mathrm{g} \min )$ and $\beta(\mathrm{g} / \mathrm{mg})$ are the initial adsorption rate constant and desorption rate constant, respectively. Kinetics of adsorption of atrazine with UBC, 2-ABC and 2-BBC also followed Elovich equation with the plots of $q_{t}$ against $\mathrm{ln} \mathrm{t}$ giving straight lines with fairly high correlation coefficient (Fig. 6d). The Elovich constants $\alpha, \beta$ computed from the plots are $3.95 \times 10^{12} \mathrm{mg} / \mathrm{g}$ min, $0.287 \mathrm{~g} / \mathrm{mg}$ for UBC, $1.926 \times 10^{52} \mathrm{mg} / \mathrm{g} \mathrm{min}, 90.91 \mathrm{~g} / \mathrm{mg}$ for $2-\mathrm{ABC}$ and
Table 3 Thermodynamics Parameters

\begin{tabular}{lclllllll}
\hline $\begin{array}{l}\text { Adsorbent } \\
\text { temp }(\mathrm{K})\end{array}$ & $\Delta H(\mathrm{~kJ} / \mathrm{mol})$ & $\Delta S(\mathrm{~J} / \mathrm{mol})$ & \multicolumn{6}{l}{$\Delta(\mathrm{kJ} / \mathrm{mol})$} \\
\cline { 3 - 8 } & & & 308 & 313 & 318 & 323 & 328 & 333 \\
\hline UBC & -760.02 & -2.215 & -4724.9 & -4717.4 & -4279.7 & -3445.8 & -2322.3 & -938.3 \\
2-ABC & -1057.08 & -3.110 & -6263.6 & -6218.8 & -4449.1 & -4252.9 & -2322.3 & -1132.9 \\
2-BBC & -252.73 & -0.581 & -5115.5 & -4717.4 & -4655.7 & -4544.5 & -4318.7 & -3982.5 \\
\hline
\end{tabular}


$6.58 \times 10^{44} \mathrm{mg} / \mathrm{g}$ min, $3.676 \mathrm{~g} / \mathrm{mg}$ for $2-\mathrm{BBC}$ as given in Table 2 . These values might also explain why the adsorption process took longer time to reach equilibrium.

The comparison of correlation coefficients obtained for pseudo-second-order kinetic model $\left(R^{2}=0.999,1.000\right.$ and 1.000) explained the adsorption process better than Elovich model $\left(R^{2}=0.955,0.881\right.$ and 0.780$)$. However, in overall, the pseudo-second-order kinetic model still appears to be the rate determining model as it is the model
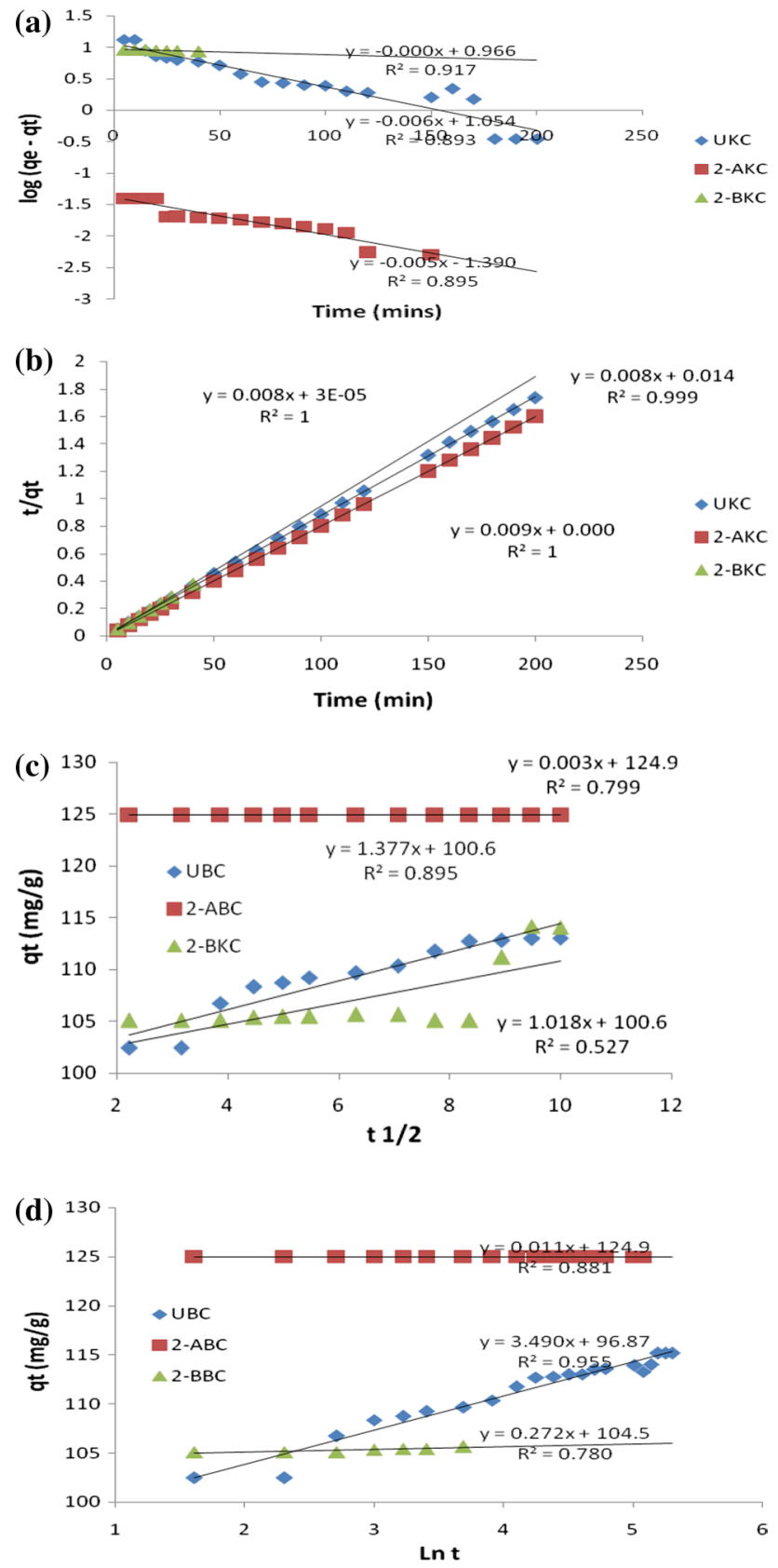

Fig. 7 Kinetic models fit of adsorption of atrazine molecule with the UBC, 2-ABC and 2-BBC. a Pseudo-first; b pseudo-second; c intraparticle; d Elovich with the highest correlation coefficient values (Table 2, Fig 7).

\section{Thermodynamics studies}

Thermodynamic parameters can provide useful and strong information about the mechanism involved in the adsorption process. The characterization of equilibrium system like the adsorption system in this study is described by thermodynamic parameters such as free energy $(\Delta G)$, enthalpy $(\Delta H)$ and entropy $(\Delta S)$ changes which were calculated using Eqs. 12-14.

$$
\begin{aligned}
& \ln K=-\frac{\Delta H}{R T}+\frac{\Delta S}{R} \\
& \Delta G=-R T \ln K \\
& K=\frac{C_{i}-C_{f}}{C_{i}}
\end{aligned}
$$

where $R$ is gas constant $\left(8.314 \mathrm{Jmol}^{-1} \mathrm{~K}^{-1}\right)$, T is absolute temperature in $K, C_{i}$ is initial concentration before adsorption, and $C_{f}$ is concentration left in solution after adsorption. The thermodynamic plots obtained from Eqs. 12 to 14 are depicted in Fig. 8, while the values of $\Delta G, \Delta H$ and $\Delta S$ for the three adsorbents are listed in Table 3.

As seen from Table 3, the negative values of the enthalpy, entropy and free energy changes indicate exothermic nature of the processes, decrease in disorderliness and that the adsorption processes are spontaneous and feasible.

Moreover, the $\Delta H$ values of adsorption of atrazine with UBC $(-760.02 \mathrm{~kJ} / \mathrm{mol}), 2-\mathrm{ABC}(-1057.08 \mathrm{~kJ} / \mathrm{mol})$ as well as $2-\mathrm{BBC}(-252.73 \mathrm{~kJ} / \mathrm{mol})$ suggest that the process is exothermic nature. Furthermore, 2-BBC shows higher adsorption enthalpy changes than the 2-ABC and UBC, which signifies that $2-\mathrm{BBC}$ has a stronger affinity for atrazine than $2-\mathrm{ABC}$ and $\mathrm{UBC}$.

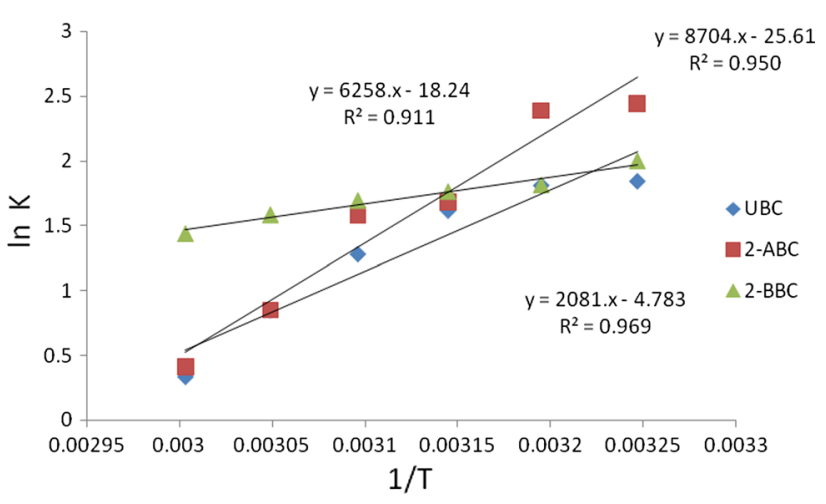

Fig. 8 Thermodynamic plot of adsorption of atrazine with the claytypes

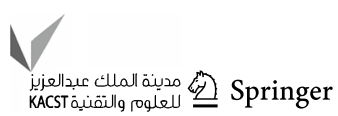


The thermodynamic results obtained in this study are in agreement with the results observed by other researchers. The $\Delta H$ values of $-29.46 \mathrm{~kJ} / \mathrm{mol}$ and $-17.76 \mathrm{~kJ} / \mathrm{mol}$ obtained for active carbon fibre and granular active carbon in the adsorption of $P$-nitrophenol as well as $\Delta H$ values of $-4.4347 \mathrm{~kJ} / \mathrm{mol}$ and $-7.766 \mathrm{~kJ} / \mathrm{mol}$ in the adsorption of $P$-nitrophenol using natural zeolite and natural bentonite have been reported (Nwosu et al. 2017; Varank et al. 2012).

\section{Conclusion}

2-ABC adsorbed atrazine better than UBC and 2-BBC. The amounts of atrazine adsorbed by the three adsorbents were strongly influenced by experimental conditions. Langmuir isotherm best described the adsorption of atrazine on the UBC, 2-ABC and 2-BBC, while pseudo-second-order kinetic model fitted well with the experimental data of the three bentonite clay-types. Intra-particle diffusion alone could not describe the rate determining mechanism for the adsorption processes. The adsorption process was found to be exothermic and spontaneous. Thus, there is high potential ability of bentonite clay-types to remove atrazine from aqueous solution and could also be utilized for removal of small size molecules from industrial effluents.

Open Access This article is distributed under the terms of the Creative Commons Attribution 4.0 International License (http://creativeco mmons.org/licenses/by/4.0/), which permits unrestricted use, distribution, and reproduction in any medium, provided you give appropriate credit to the original author(s) and the source, provide a link to the Creative Commons license, and indicate if changes were made.

\section{References}

Abu-Elella R, Ossman M, Farouq R, Abd- Elfatah M (2015) Used motor oil treatment: turning waste oil into valuable products. Int J Chem Biochem Sci 7:57-67

Ahmed AA, Hameed BH, Aziz N (2007) Isotherms, kinetic and thermodynamic of acid dye adsorption on activated palm ash. Chem Eng J 133(1):195-203. https://doi.org/10.1016/j.cej.2007.10.032

Amin E, Khairul A, Hadi N (2010) Physicochemical characteristics of phosphoric acid stabilized bentonite. Engineering 15c:327-336

Aroke U, Abdulkarim A, Ogunbunka R (2013) Fourier transform infrared characterization of kaolin, granite, bentonite and barite. Chemical engineering programme. ATBU J Environ Technol $6: 1-32$

Austin E, Hoang KT (2009) Evaluation of gasmet TMDX 4015 series Fourier transform infrared gas analyzer, DTIC document. http:// www.dtic.mil/get-tr-doc/pdf?AD=ADA504486

Bhasker JS, Gopalakrishnarao P (2010) Fourier transform infrared spectroscopic characterization of kaolinite from Assan and Meghalaya, Northeastern India. J Mod Phys 1:206-210

Bohli T, Fiol N, Villaescusa I, Ouederni A (2013) Adsorption on activated carbon from olive stones: kinetic, and equilibrium of phenol removal from aqueous solution. J Chem Eng Process Technol 4(6):1-5. https://doi.org/10.4172/2157-7048.1000158

Burleigh MC, Markowitz MA, Spector MS, Gaber BP (2002) Porous polysilsesquioxanes for the adsorption of phenol. Environ Sci Technol 36:2515. https://doi.org/10.1021/es011115

EPA (1990) Interim methods for development of inhalation reference concentrations. Office of Health and Environmental Assessment, Office of Research and Development, Environmental Criteria and Assessment Office. U.S. Environmental Protection Agency, Washington, DC pp 8-90

Gómez-Tamayo MM, Marcías-García A, Díaz- Díez MA, CuerdaCorrea EM (2008) Adsorption of $\mathrm{Zn}(\mathrm{II})$ in aqueous solution by activated carbons prepared from evergreen oak. J Hazard Mater 153(1):28-36. https://doi.org/10.1016/j.jhazmat.2007.08.012

Georges-Ivo EE (2005) Fourier Transform infrared spectrophotometry and X-ray powder difractometry as complementary techniques in characterizing clay size fraction of kaolin. J Appli Sci Environ Manag 9(2):43-48

Halif NA, Daud WMAW, Noor IM, Hassan CRC (2007) Effect of temperature on the adsorption of 4-nitrophenol onto palm shell based activated carbon. AEESEAP J Eng Educ 31(2):23-28. http://mjcs.fsktm.um.edu.my/detail.asp?AID $=559$

Hatem AA, Jamil MM, Ahmad AA, MRB Abas (2012) Adsorption of 4-nitrophenol on palm oil fuel ash activated by amino silane coupling agents. Desalin Water Treat 40(1-3):159-167. https ://doi.org/10.1080/19443994.2012.671162

Isci S, Unlu C, Atici O, Gungor A (2006) Rheology and structure of aqueous bentonite polyvinyl alcohol dispersion. J Indian Acad Sci 29(5):454-456

Jone TW, Kemp WM, Stevenson JC, Means JC (1982) Degradation of atrazine in estuarine water/sediments systems and soils. J Environ Qual 11(4):628-638

Kauffmann C, Shoseyov O, Shpigel E, Bayer EA, Lamed R, Shoham J, Mandelbaum RT (2000) Novel methodology for enzymatic removal of atrazine from water by CBD-fusion protein immobilized on cellulose. Environ Sci Technol 34(7):1292-1296

Kolpin DW, Kalkhoff SJ, Goolsby DA (1997) Occurrence of selected herbicides and herbicide degradation products in Iowa's ground water. Ground Water 35:679-688

Li L, Liu F, Jing X, Ling P, Li A (2011) Displacement mechanism of binary competitive adsorption for aqueous divalent metal ions onto a novel IDA-chelating resin: isotherm and kinetic modeling. Water Res 45(3):1177-1188

Liu N, Charrua AB, Weng CH, Tuan X, Ding F (2015) Characterization of biochars derived from agricultural wastes and their adsorptive removal of atrazine from aqueous solution: comparative study. Bioresour Technol 198:55-62. https://doi. org/10.1016/j.biortech.2015.08.129

Mall ID, Vimal CS, Nitin KA (2006) Removal of Orange-G and Methyl Violet dyes by adsorption onto bagasse fly ash-kinetic study and equilibrium isotherm analyses. Dyes Pigments 69(3):210-223

Miller SM, Sweet CW, Depinto JV, Hornbuckle KC (2000) Atrazine and nutrients in precipitation: results from the lake Michigan mass balance study. Environ Sci Technol 34:55-61. https://doi. org/10.1021/es990486n

Mullan D (2006) Scanning electron microscopy 1928-1965. Scanning 17(3):175-185. https://doi.org/10.1002/sca.4950170030

Nwosu FO, Ajala OJ, Owoyemi RM, Raheem BG (2018) Preparation and characterization of adsorbents derived from bentonite and kaolin clays. Appl Water Sci. https://doi.org/10.1007/s1320 1-018-0827-2 
Nwosu FO, Adekola FA, Salami AO (2017) Adsorption of $N$-nitrophenol (PNP) using pilli nut shell action. Pak J Anal Environ Chem 18(1):69. https://doi.org/10.21743/pjaec/2017.06.07

Patel JB, Sudhakar P (2008) Adsorption of mercury by powdered corn cobs. Electr J Environ Agric Food Chem 7(14):2735-2742

Ramachandran VS, Beaudoin JJ (2008) Handbook of analytical techniques in concrete science and technology: principles, techniques and applications. William Andrew, Norwich, pp 564-573

Sathishkumar M, Binupriyu AR, Kavitha D, Yun SE (2007) Kinetic and isothermal studies on liquid-phase adsorption of 2,4-dichlorophenol by palm pith carbon. Bioresour Technol 98(4):866-873. https://doi.org/10.1016/j.biortech.2006.03.002

Tang D, Zheng Z, Lin K, Luan J, Zhang J (2007) Adsorption of $p$-nitrophenol from aqueous solution onto activated carbon fiber. J Hazard Mater 143(1):49-56. https://doi.org/10.1016/j.jhazm at.2006.08.066

Tempkin MI, Pyzhev V (1940) Kinetic of ammonia synthesis on promoted iron catalyst. Acta Phys Chim USSR 12(1):327
Tomlin, Clive and British Crop Protection Council (2000). In: Tomlin CDS (ed) The pesticide manual: a world compendium, 12th edn. British Crop Protection Council, Farnham, Surrey, UK

Varank G, Demir A, Yetimezsoy K, Top S, Sekman E, Bilgili MS (2012) Removal of 4-nitrophenol from aqueous solution by natural low-cost adsorbents. Indian J Chem Technol 19:7. https://hdi. handle.net/123456789/13498

Xu L, Zang H, Zhang Q, Chen Y, Wei Y (2013) Photocatalytic degradation of atrazine by H3PW12O40/Ag-TiO2: kinetic, mechanism and degradation pathways. Chem Eng J 232:174-182. https://doi. org/10.1016/j.cej.2013.07.095

Publisher's Note Springer Nature remains neutral with regard to jurisdictional claims in published maps and institutional affiliations 